This is an electronic reprint of the original article. This reprint may differ from the original in pagination and typographic detail.

Author(s): Ojala, Arto; Helander, Nina

Title: $\quad$ Value creation and evolution of a value network: A longitudinal case study on a Platform-as-a-Service provider

Year: $\quad 2014$

Version:

Please cite the original version:

Ojala, A., \& Helander, N. (2014). Value creation and evolution of a value network: A longitudinal case study on a Platform-as-a-Service provider. In Proceedings of the 47th Hawaii International Conference on System Sciences (HICSS 2014) (pp. 975984). IEEE. Proceedings of the Annual Hawaii International Conference on System Sciences. https://doi.org/10.1109/HICSS.2014.128

All material supplied via JYX is protected by copyright and other intellectual property rights, and duplication or sale of all or part of any of the repository collections is not permitted, except that material may be duplicated by you for your research use or educational purposes in electronic or print form. You must obtain permission for any other use. Electronic or print copies may not be offered, whether for sale or otherwise to anyone who is not an authorised user. 


\section{Value creation and evolution of a value network: A longitudinal case study on a Platform-as-a-Service provider}

\author{
Arto Ojala \\ University of Jyväskylä \\ arto.k.ojala@jyu.fi
}

\author{
Nina Helander \\ Tampere University of Technology \\ nina.helander@tut.fi
}

\begin{abstract}
Current research on cloud computing emphasizes the important role of Platform-as-a-Service (PaaS) providers. However, little is known about how PaaS providers can offer value to the content providers and firms operating the platform. The findings demonstrate how a small PaaS provider in the cloud gaming market was able to develop a strong position in the value network by offering direct and indirect value to its partners. The findings also reveal how the firm developed its value network over fourteen years, from a complex network with several actors to a very simple value network which included only partners of prime importance.
\end{abstract}

\section{Introduction}

In cloud computing, different service providers cooperate with each other to create value for other firms and end-users. This makes the business environment complex and networked, since a firm is, in many cases, dependent on other service providers in the market. Thus, a cloud service may be facilitated by a mutual dependence among Software as a Service (SaaS) providers, Platform as a Service (PaaS) providers, and Infrastructure as a Service (IaaS) providers (Figure 1$)^{1}$. To operate successfully with partners and customers in the cloud ecosystem, a firm has to consider the value that it offers for other firms in the network, and how this value can be delivered to the customers and end-users.

Figure 1: Different service layers/providers that enable the cloud service

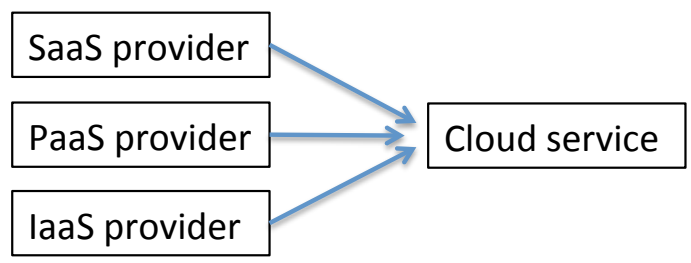

According to Allee [1], to operate successfully in a value network, a firm needs to identify the value of its offering, including how this value can be

\footnotetext{
${ }^{1}$ In practice, a single company may provide all the layers (SaaS, PaaS, IaaS), or the different layers may be provided by different companies [16].
}

delivered so that it benefits all the actors in the network. By defining the value network, a firm can map all the actors that could benefit from its product or service offering, and add value to the firm's own offering. This is extremely important for platform providers. A platform provider needs to cooperate with other firms that provide complementary products and services for the platform. Together they form a value network that increases the value of the innovation to end-users $[2,3]$.

Current studies on cloud computing have mainly focused on SaaS providers [4] whereas PaaS and IaaS providers have gained less attention. However, the importance of PaaS providers have been noted in several works on cloud computing [5, 6, 7, 8]. Firms in PaaS markets commonly act between SaaS and IaaS providers, i.e. actors that make the PaaS situation challenging in the market. As highlighted by Beimborn et al. [7], PaaS firms have to develop extra value for content providers in such a way as to increase the attractiveness of the platform. In addition, they have to cooperate with IaaS providers which operate their platform on servers, and which deliver the content to end-users.

While research on cloud computing has provided a good understanding of different service providers and of the value of cloud computing [4, 25], the literature has not elaborated how the different service providers act and develop value for each other or for end-users. In this regard, one can draw on industrial network theory $[9,10]$ and research on value networks $[1,11,12]$ in order to understand firms' network formation, their activities in the network, and a number of dimensions of value. This paper seeks to contribute to information systems (IS) literature by examining: 1) the direct and indirect value that a PaaS provider generates to its partners in the network, 2) how a PaaS provider develops its position in the value network, and 3) how the value network evolves over time.

To obtain insights into the topic, the research reported here applied a longitudinal single-case study method, based on 13 interviews and other empirical material covering the entire history of the firm over a period of 14 years. The case firm selected for this study presents an illustrative example of how a small firm can acquire a good market position by developing its network and offering value for its partners in a new and emerging field of business, namely cloud gaming. From the practical point of view, this study provides insights on how a small 
technology start-up with an innovative product can develop a plausible market position in the game industry, which tends to be dominated by wellestablished multinationals. In addition, this paper expands from an earlier study by Ojala and Tyrväinen [25], which focused on the general benefits of value networks in cloud computing from a practical point of view. The present paper provides more theoretical and detailed insights on how PaaS providers can build their value network, and on the direct and indirect values within the network.

The paper starts with a theoretical discussion on the context of the study, i.e. cloud computing and PaaS, looking also at business networks and value creation. The research methods and empirical data are presented. Case study findings and the results of the analysis are also presented, prior to some conclusive thoughts at the end of the paper.

\section{Literature review}

In the following section, we present some perspectives on cloud computing and PaaS. Thereafter, we refer to some of the literature on business networks and value creation. This theoretical discussion leads to the tools we adopt for empirical analysis of value networks in the context of PaaS in cloud gaming.

\subsection{Cloud computing and PaaS}

In cloud computing, users obtain access to computing resources, storage space, and software applications via the Internet as a service. Cloud computing includes three service layers. These consist of (i) Infrastructure as a Service (IaaS), which provides the necessary hardware, computation and storage capacity, (ii) Platform as a Service (PaaS), which provides software development tools plus an application execution environment, and (iii) SaaS, which provides applications on top of PaaS and IaaS $[4,13]$. Thus, cloud computing refers to the provision of computing capacity, storage capacity, and applications as a service across the Internet. The International Data Corporation (IDC) defines cloud computing as "consumer and business products, services and solutions delivered and consumed in real-time over the Internet" [14].

While PaaS presents an invisible layer to the endusers, it creates the heart of cloud computing by enabling a virtual platform for the development and deployment of software applications. In practice, PaaS offers "a complete set of technologies which are required to develop and to operate SaaS applications" [7, p. 381]. PaaS has several advantages for software developers, such as increasing programmer productivity, shorter development time for software, reduction in software development costs, and improved marketing and sales opportunities [6, 7]. In addition, PaaS typically supports a multi-tenancy architecture in which an IaaS provider hosts a single instance of the software on a server that can be used by multiple users simultaneously [7].

According to Boniface et al. [8], PaaS stakeholders can be divided into three groups, i.e. (i) PaaS hosters, (ii) PaaS providers, and (iii) PaaS users. In the context of this study, network operators, functioning as IaaS providers, act also as PaaS hosters that provide infrastructure for running a platform and delivering game content to end-users. The case firm, $G$-cluster, is a PaaS provider providing a platform to run game content in the cloud environment, and a software development kit (SDK) for the game developers. PaaS users are game publishers that can port their existing games to Gcluster's platform, or else develop new games directly for the platform by using the SDK.

\subsection{Networks}

In business networks, firms share common interests, which motivate them to develop relationships with each other for their mutual benefit $[10,15]$. In these networks, a firm may have relationships with different types of actors, for example with customers, distributors, suppliers, competitors, non-profit organizations, and bodies in public administration. Different kinds of resources that bring value to a firm have an important role in networks. Johanson and Mattsson [10] point out that because a firm is dependent on resources (tangible and intangible) controlled by other firms, it can compensate for its limited resources by developing its position in an existing network, or alternatively, by establishing new networks. Thus, the anticipated resources available to a firm through the network influence a potential partner's eagerness to join the network [17]. The resources can be extremely heterogeneous, and they depend on the network in question. They have attributes in many dimensions, features that lead to their adoption. One characteristic is the utilization of the resource in activities. Activities occur when actors create, combine, develop, or exchange resources. Activities, and also actors, are linked together in multiple ways. It is important to notice that networks are often intensified by new activities, changes in old activities, the rearrangement of activities or changes in the relationships between these various facets [9].

Easton [18] illustrates the basic elements of the network approach from four different viewpoints, employing metaphors: thus he identifies networks as positions, processes, structures, and relationships. The analysis of networks as positions mainly involves examination of the network from the viewpoint of a single company. Networks as structures are concretized through the 
interdependencies between the organizations concerned: the greater the interdependence of the organizations, the clearer the structure of the network [18]. Thus, there can be, as it were, "tight" networks, in which there are a great number of bonds between the actors, plus well-defined roles and functions for actors, and also "loose" networks possessing the opposite characteristics [18]. The nature of networks as processes mirrors the nature of the networks themselves: networks are stable but not static. Due to the interrelationships among actors in the network, evolutionary changes are more characteristic of networks than are radical changes [18]. In any case, it has often been observed that networks may change over time [19, 20].

The actors-resources-activities model [9] provides a solid basis for a value network analysis, as it makes it possible to identify the structure of the network and its key actors. For a firm, it is important to recognize who the actors are (or will be) in the firm's value network. The firm needs to identify the value of the firm's offering, plus how this value can be delivered in such a way as to benefit all the actors in the network. By defining the value network, a firm can map all the actors that could benefit from its offering, and the resources that they will need in order to commercialize their product/service [1, 11]. Doing this can also help a firm to avoid unnecessary partners, i.e. actors who will not add value to its product. Thus, in the value network, the ideal partner adds value to the firm's market offering, while at the same time minimizing the risk connected with partnering [21]. In fact, the process of value creation through the activities of firms is at the present time undergoing a fundamental change: there is a clear movement towards value creation in the networks of connected firms, and away from traditional value creation within a single-company or vertically integrated companies [22].

\subsection{Value}

The concepts of value, value creation, and value capture, are often utilized in discussions of modern business. For the purposes of this study it is necessary to have a solid understanding of the contents of these concepts in order to analyze the created and captured value of the network actors. In the first place, it is important to understand the kinds of elements included in the concept of value.

Taking a fairly broad perspective, the concept of value can be seen in terms of a trade-off between benefits and sacrifices [13, 23, 24]. These benefits and sacrifices can be understood in monetary terms, but they can also be seen as including non-monetary rewards, such as competence, market position, and social rewards [12]. Non-monetary costs can include, for example, the time, effort, energy, and amount of conflict to be engaged in by the customer in order to obtain the product or service.
Nevertheless, the concept of value includes also other aspects than just the most general content-based view. According to Parolini [24], it is also useful to distinguish between absolute value and differential value. The difference between absolute value and differential value is based on the assumption that it is possible to regard value as something very real and absolute, while at the same time being aware that the expectations and mental images of the value receivers are also important factors in the evaluation of value. The concept of absolute and differential value is closely linked to the notion of their being perceived benefits and sacrifices on the part of the network actor. Absolute value refers to something very real, whereas differential value refers to value as something that is not only dependent on the endcustomer's own expectations and evaluations, but is also evaluated in relation to other possible solutions. Thus, absolute value can be defined as the algebraic sum of (i) the value attributed to the absolute benefits connected with the product and (ii) the costs incurred in using the product. Differential value, on the other hand, refers to the customer's perception of the difference between two similar or substitute solutions offered by competing value networks [24]. It can be argued that the term differential value, as presented by Parolini [24], offers a context-based view on value - value is always measured, ultimately, by the value perceiver, and the perceiver will also take into account other available solutions that could fulfill her/his needs.

Whether value is monetary or non-monetary, and whether absolute or differential, it always needs a creator and a capturer. Sometimes these can be one and the same actor, but in the methodology of our study and the context of networks, it is reasonable to differentiate between the value creator and the value capturer. It should be noted, however, that each actor in the value network needs to both create and capture if she/he is to build a long-term and successful value network.

Both value creation and value capture can be viewed also from a functional perspective. This kind of function-oriented viewpoint on value, introduced by Walter et al. [12], offers a more complete view on the types of activities that actors may perform in order to create more value for network members. According to function-oriented value analysis, a company may gain value from its relationships by both direct and indirect functions [12]. Direct functions bring value that is easier to measure financially and to realize in the context of the relationship between the company and the customer. Indirect functions, by contrast, require also the input of third parties, and the outcomes are less easy to measure financially. The notion of value-creating functions of this kind can illuminate discussion concerning which activities and functions are likely to create value. 


\section{Research method}

It was recognized that the research method selected for a study of the type envisaged should be one that would make it possible to understand social phenomena in their natural settings, enable an indepth and longitudinal investigation of complex phenomena, and capture cause-and-effect relationships. Based on these considerations, we selected a longitudinal case study method [26, 27, 28]. The longitudinal single-case method is useful in providing detailed [29] and empirically rich data [30] connected with a phenomenon. A longitudinal case study also facilitates an examination of changes within a firm [27, 31] and its networks [32].

The data collection for this study incorporated several types of empirical material covering the whole history of the case firm (see Table 1), from 2000 to 2013 . The interviews with the employees of the firm took place in 2005, 2010, 2011, 2012, and 2013. Because the case firm was relatively small, the interviews with the CEO were the main source of information. However, to avoid bias from individual opinions [33], eight other employees with a variety of positions in the firm, were interviewed; thus different organizational levels were addressed, ranging from a software developer to a vice president of the company. Altogether, the study included 13 interviews, each lasting 45-90 minutes. All the interviews were recorded and the first author transcribed them verbatim, using a word processing program. Thereafter, the complete transcripts were sent back to the interviewees for review. For the most part the interviewees accepted the transcripts in the form in which they were sent. However, in some cases, the interviewees gave some minor comments related to the misspelling of a partner's name or to some particular wording. In addition to the face-toface interviews, telephone and e-mail communication was used to collect further information, and to clarify inconsistent issues if necessary. These communications were also added to the case-study database. To avoid retrospective bias [33], we used several types of early records, including the firm's private placement memo from the year of its establishment and press releases from the firm's early days, in order to support our interviews. In addition, if an interviewee was unsure about an important event, we asked the interviewee to check his/her emails to recall how the events progressed. This procedure worked well, as all the interviewees had saved past emails. To ensure the accuracy of the value networks, the diagrams drawn (see Figures 24) were validated by the firm's CEO. The authors gave him access to the figures illustrating the networks; thereafter we discussed the figures and made some minor changes based his comments. In the data collection we also used many types of secondary information covering the whole history of the firm (Table 1). All this helped us to arrive at an extensive and detailed historical description of the firm, its network partners, and the changes in the network. In using this information, we also conducted triangulation of the information [34], though comparison of the interview data with other information gathered on the case firm.

The case firm was selected for this study to ensure the fit of a single-case study with the research questions. The case firm acted as a PaaS provider in a new business area, i.e. cloud gaming. It also had a relatively long history in the cloud gaming markets, thus facilitating a longitudinal perspective. In combining these features, the case firm presents a fairly extreme and unusual case [28].

The method utilized in the data analysis was content analysis. The analysis of the case data consisted of three concurrent flows of activity [34]: (i) data reduction, (ii) data displays, (iii) conclusiondrawing/verification. In (i) the data reduction phase, the data were given focus and simplified through compilation of a detailed case history of the firm. This is in line with Pettigrew [27], who suggests that organizing incoherent aspects in chronological order is an important step in understanding the causal links between events. In (ii) the data display phase, we drew figures to describe the value networks of the firm in 2005, 2010, and 2013. In (iii), the phase of conclusion drawing and verification, we concentrated on identifying the aspects that appeared to have significance for this study. At this stage we noted regularities, patterns, explanations, and causalities related to the phenomena.

Table 1: Empirical material used in this study

\begin{tabular}{|c|c|c|}
\hline Data source & $\mathrm{N}$ & Year(s) \\
\hline $\begin{array}{l}\text { Interviews with the } \\
\text { CEO }\end{array}$ & 5 & $\begin{array}{l}2005(\mathrm{~N}=1), 2010(\mathrm{~N}=2), 2011 \\
(\mathrm{~N}=1), \\
2012(\mathrm{~N}=1)\end{array}$ \\
\hline 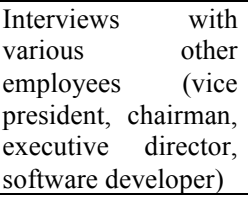 & 8 & $\begin{array}{l}2005(\mathrm{~N}=1), 2010 \quad(\mathrm{~N}=6), 2013 \\
(\mathrm{~N}=1)\end{array}$ \\
\hline Press releases & 43 & $\begin{array}{l}2002(\mathrm{~N}=1), 2003(\mathrm{~N}=1), 2004 \\
(\mathrm{~N}=4), \\
2005(\mathrm{~N}=15), 2006(\mathrm{~N}=5), 2008 \\
(\mathrm{~N}=2), \\
2010(\mathrm{~N}=1), 2011 \quad(\mathrm{~N}=2), 2012 \\
(\mathrm{~N}=8), \\
2013(\mathrm{~N}=4)\end{array}$ \\
\hline Brochures & 2 & $2009(\mathrm{~N}=1), 2010(\mathrm{~N}=1)$ \\
\hline Web-sites & 1 & $2005-2012$ \\
\hline $\begin{array}{l}\text { Private placement } \\
\text { memo }\end{array}$ & 1 & 2000 \\
\hline $\begin{array}{l}\text { Video advertisement } \\
\text { material }\end{array}$ & 3 & $2013(\mathrm{~N}=3)$ \\
\hline
\end{tabular}




\section{Background of the case firm}

$G$-cluster develops interactive gaming platforms and games-on-demand services as a PaaS provider. Throughout its history (from 2000 onwards), Gcluster has been relatively small firm, employing 1040 persons. The business concept of G-cluster was based on what was then (in 2000) a fairly new way to provide PC and console games to players. Traditionally, games are installed on a computer or a game console which runs the game. In the G-cluster business model, by contrast, games are run on a platform; this platform is operated by the game servers belonging to an IaaS provider. It is these servers that transmit the game content as an MPEG stream to the devices of end-users, over the broadband network. The client devices receive the stream, display the game, and transmit users' commands back to the game servers. Thus, Gcluster's gaming platform makes it possible to bring games to the cloud environment. Because G-cluster's service requires very fast broadband connections and networking with other actors in the market, it took several years before the company was able to commercialize its service.

\subsection{The value network in 2005: the starting point}

The value network of G-cluster in 2005 is presented in Figure 2. The figure shows the macro position of G-cluster in the value network, displaying all the partners that they were acting with directly. This value network shows the network at the time when they commercialized their product, i.e. when it became available in the markets. First of all, Gcluster needed content for its gaming platform. As a small firm, it was not able to provide its own games or to compete against game publishers. To acquire game content, G-cluster started to network actively with game publishers, which developed PC or console games and licensed games for its platform. Hence, the game publishers acted as content providers, providing game content for G-cluster's platform.

After licensing the game, G-cluster ported the game code so that it was able to run it on its platform. However, G-cluster did not purchase the games; instead it made an agreement with the game publishers according to which they would get a negotiated percentage from the revenue that the games earned. Thus, the earning logic was based on revenue sharing. In many cases, the potential financial income was insufficient, and G-cluster had to demonstrate other benefits - benefits that would bring value to the game publishers if they started to use G-cluster's gaming platform. These benefits included, for instance, (i) avoiding piracy, (ii) avoiding second-hand markets, (iii) more durable markets for games, (iv) flexible revenue models. Because the game content was run in the cloud environment, and streamed to end users, the endusers did not get the game code. This made illegal copying impossible. Piracy is a serious problem in the games industry, and prevention of illegal copying was a motivating factor for the game publishers. Delivering the game content virtually also made second-hand markets impossible. A major proportion of the annual sales of games come from second-hand markets. However, game publishers do not benefit from these markets, as their revenue comes only from the sales of new games. In G-cluster's virtual store, shelf space costs nothing. This makes it possible to make games available to the end-user for a longer time, as compared to traditional game stores in which the life cycle of a game is relatively short (8-12 weeks) and shelf-space is expensive. G-cluster's gaming platform facilitates a variety of revenue models. Unlike the traditional model, in which an end-user buys a game from a store, G-cluster's service made it possible to rent the game. Thus, in following this path, the game could be rented for an hour, a day, or a week, or it could form part of some larger games package.

In addition to game content, G-cluster needed IaaS providers who could operate their platform on servers. For this purpose they needed to find network operators who had a broadband network with the IPTV feature, as there was a need for fast two-way data transfer. Network operators were observed to have good marketing channels and a pre-existing customer base. Furthermore, the network operators offered a well-known brand that could be used for marketing purposes. In some cases, the operators also motivated game publishers to make their games available for G-cluster's platform. These factors all were important for G-cluster, since the network operators made available resources that G-cluster could not acquire otherwise. However, the move towards cooperation with large companies such as network operators was not easy. G-cluster needed to show the value of their product for network operators. In addition to monetary benefits, The Gcluster service offered a good opportunity to extend the network operators' existing product portfolio to end-users. By using G-cluster's gaming platform, network operators had more content to offer their customers, and were able to differentiate their offering from that of competitors. One informant made the following comment:

"Globally, most of the network operators are in a market situation where they send a letter to customers saying that they have doubled the connection speed of the broadband network, and decreased the price of the connection. So, in this kind of situation it is difficult to increase revenue. However, valueadding services such as video-on-demand 
and our games-on-demand services are one way to increase the offering and the revenue."

To get into the market and achieve cooperation with network operators, G-cluster needed help from other firms. These firms were (i) video-on-demand service providers, (ii) set-top box manufacturers, and (iii) middleware software providers. For video-ondemand service providers, G-cluster's game platform made possible a new feature that did not compete with their existing services, but which allowed them to offer more content for network operators. In-line, set-top box manufacturers needed new functions for their devices (which they could introduce to network operators) and G-cluster's platform brought extra value for them. Middleware software providers, selling software to network operators, benefited from G-cluster's platform, as they were able to show that in addition to video-on-demand and other TVchannel services, their software could also handle game-on-demand services. The cooperation among these three different types of firms was based mainly on the mutual benefits that the relationships provided rather than on monetary benefits. One informant expressed this as follows:

\begin{abstract}
"There were mutual benefits. We had the same target customers, network operators, the same technical requirements, etc. For us, these firms provided more sales resources, that is, more people who could inform the markets [network operators] about our product. For them, the benefit was in getting more content into their product and in that way, more features to offer to the network operators."
\end{abstract}

"For us it was quite an easy situation. We made contact with all possible firms who could benefit from our product and we found many firms who were willing to enter into cooperation with us... because our product was so unique. So there were no corresponding products in the market."

These firms had existing relationships with network operators, and they helped G-cluster to achieve a contract with the key decision makers among the operators. In addition, by cooperating with video-on-demand service providers, G-cluster gained an invoicing system for their service (as the requirements for invoicing corresponded). One informant expressed this as follows:

"Video-on-demand service providers have to provide some kind of integration of their invoicing system for network operators. We liked the fact that the payment would be easy [for the end-users], meaning that it is useful if all the services are included in the same invoice from the network operator. Thus, we had corresponding requirements in integrating the invoicing system for our game service."

In 2005, the portals gave PC users access (a website) to the G-cluster's games-on-demand service. By using a portal's website, PC players were able to $\log$ in to the service and to select the game that they would like to play. The portals also took care of marketing and billing the customers via the invoicing system, which was integrated with their own service. For the portals, G-cluster's service brought revenue without requiring any investment, and it was easily integrated with their current business. One interviewee highlighted this as follows:

"For the portals, it was very easy to integrate our service with their own without any additional investment. They just needed to add a link to their website, and the link gave access to our service"

Figure 2: The value network in 2005.

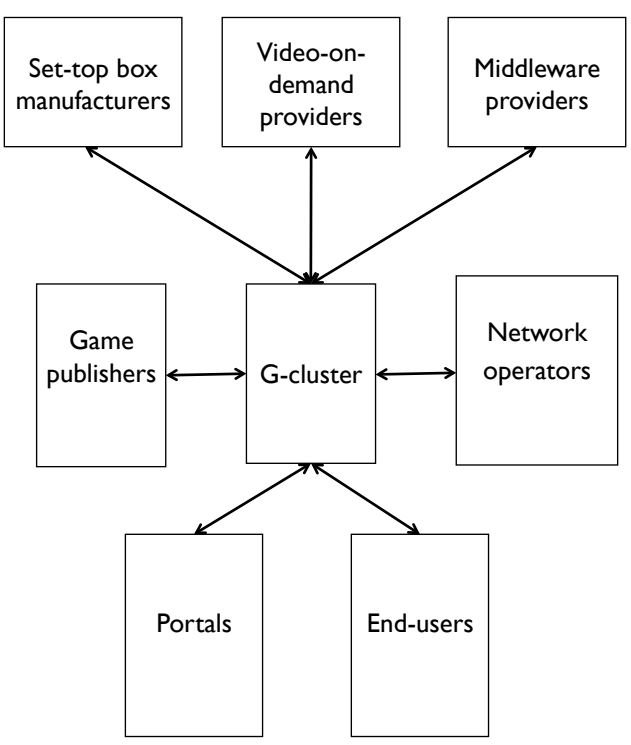

\subsection{The value network in 2010: a changed landscape}

The value network of G-cluster in 2010 is shown in Figure 3. Over a five-year period, important changes had occurred in the market environment and in G-cluster's product, and these impacted on the value network. First of all, G-cluster changed its target group from PC users to solely IPTV users. This decision was the consequence of increasing competition in the PC game markets, where simpler games have increasingly become free to the end-user. On the other hand, "heavy" players, those who play 
more complex games, tend to buy games from a store, and they are willing to invest in game consoles and other equipment. In addition, during the five-year period, the network operators had increased their IPTV offering substantially and there was a growing customer base with reliable IPTV connections. In this situation, G-cluster started to focus solely on the IPTV market.

As a second aspect, G-cluster developed its product further, and it now offered a ready-made product for the network operators. This meant that the product included components that had previously been provided by video-on-demand service providers or by network portals, such as an invoicing system, plus a user interface (menu) that enabled users to select games from its virtual games store. By including these components within the product, they became less dependent on third parties. G-cluster also started to provide its SDK for game publishers, allowing game developers to code their games directly for G-cluster's platform.

Because of these changes, the benefits previously brought by video-on-demand service providers, settop box manufacturers, middleware software providers, and portals became less valuable, and in fact these firms were now excluded from the value network. The comprehensiveness of the product range had allowed better access to the network operators, and as a result, there was no longer a need for many intermediaries. In addition, over a period of five years, G-cluster had come to know the network operators better, and thus it could more readily make direct contact with them. The change in the target customers, from PC users to IPTV users, and to an individualized menu, made it possible to remove portals from the value network. This also brought monetary benefits, since there were now fewer firms sharing the revenue from end-users. All in all, one can see that the decisions taken here had the potential to i) improve the competitiveness of the service, ii) increase control over the service, and iii) produce additional revenue.

In 2010, G-cluster started to cooperate with a large and well-known server manufacturer. This cooperation provided mutual benefits for both firms, even if there were no business activities (i.e. a buyercustomer relationship) between G-cluster and the server manufacturer. The point here was that compared to earlier partners, this cooperation brought in a more reliable and influential partner, one that could market the service further to IPTV operators. Cooperation with such a well-known server manufacturer could help the firm to embark on negotiations with new network operators. This increased G-cluster's marketing and sale resources, due to the fact that the server provider already knew IPTV operators around the world, and was conducting business with them. The cooperation also helped in getting negotiations under way with the right people on the customer side, with no need to waste time in various meetings before finding the right contact people from the target organization. Gcluster is a very small firm compared to the network operators, so cooperation with a large and wellknown server manufacturer added credibility to its business negotiations. Conversely, by including Gcluster's technology within its servers, the server manufacturer obtained added value, and this was something it could use in selling its servers to network operators. According to one interviewee:

\begin{abstract}
"Our product is remarkably beneficial to firms that sell servers to network operators. They can say to the network operators that by making a small additional investment, they can get an infrastructure that can be used to deliver our games-on-demand service."
\end{abstract}

Figure 3: The value network in 2010.

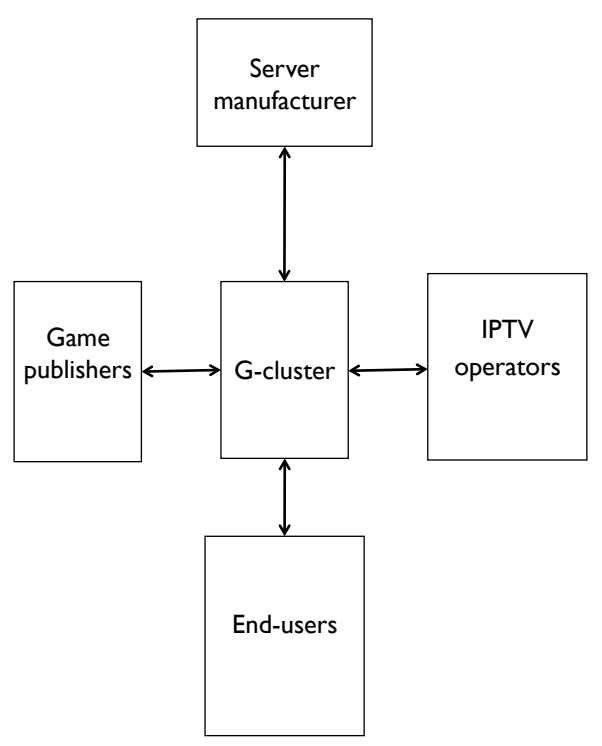

Because G-cluster's value network limited its operations only to IPTV operators, the firm brought a cloud gaming console, the "G-cluster gaming machine" to the market in 2013. The console was a small physical device that enabled end-users to have access G-cluster's game service without having an IPTV connection. Thus, the console worked over any wireless network if the broadband connection was fast enough. This expanded G-cluster's value network to operators without IPTV services, and it made G-cluster's service available to all network operators, as it was no longer tied to IPTV. One informant expressed this as follows:

"IPTV slowed down the business...some operators do not have IPTV services or there might be an end-user who had IPTV services from a competing operator. By using our game console, end-users are not tied to IPTV, it is a totally separate service." 
Another change in the value network was that cooperation with the server manufacturer no longer existed (Figure 4). Because G-cluster now had existing, well-known operators as their reference customers, they did not need the service manufacturer or other third parties to reassure operators about their service. Hence, the number of actors in the network actually decreased, at the same time as they were able to increase the number of the most critical partners, i.e. the game publishers and network operators.

Figure 4: The value network in 2013.

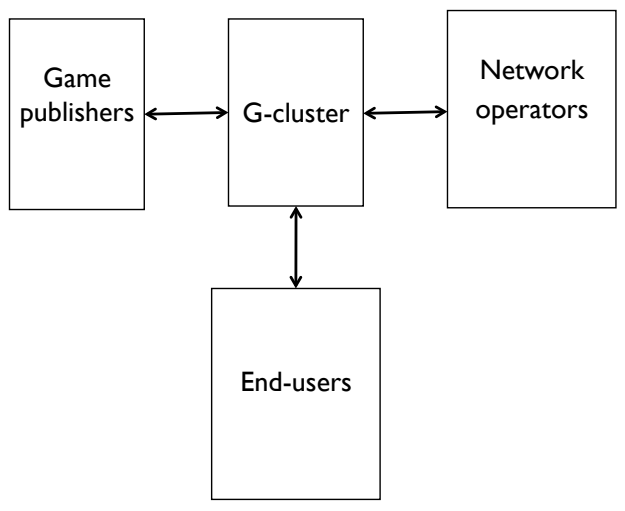

\section{Discussion}

The evolution of the value network was evident in the case study. This is a typical process for networks, caused by a change in the value creation logic and by the consolidation of the relationships between network actors. As the case demonstrates, G-cluster initially cooperated with several kinds of partners. This was necessary if the company was to gain a better position in the value network and market their platform to IaaS and SaaS providers. For this purpose, they needed to demonstrate the value of their platform for several partners in the network. The direct and indirect values between the various different actors in the each micro position are shown in Table 2.

Based on the findings, the direct value was related, in addition to monetary value, to the critical resources that G-cluster needed to commercialize its service. These included content from the SaaS providers (game publishers) for the platform, IaaS services from network operators, and a delivery channel from network operators and portals. All these were resources which it needed but which, as a small firm, it could not produce itself. Furthermore, the direct value consisted of functionalities that were not included in G-cluster's product. These were the menu for the game content (provided by portals) and invoicing system (provided by video-on-demand service providers). Thus, the firm needed access to resources controlled by other firms (cf. [10]).
According to our findings, the direct value can be divided into resources enabling the service (provided by SaaS and IaaS providers) and functionalities needed for the product. For the partners that enabled G-cluster's service, G-cluster provided mainly financial benefits as a direct value. The findings also indicate that although indirect value was not critical to G-cluster's service, it was substantial help in respect of marketing and networking. Indirect value worked in similar manner, in both directions, Gcluster gained resources for marketing and networking, and its partners gained a new feature for their services, one that they were able to use in their marketing.

Table 2: Direct and indirect value for each micro position in the value network

\begin{tabular}{|c|c|c|}
\hline Micro position & Direct value & Indirect value \\
\hline $\begin{array}{l}\text { G-cluster -> Game } \\
\text { publishers }\end{array}$ & $\begin{array}{l}\text {-Financial value } \\
\text {-SDK }\end{array}$ & $\begin{array}{l}\text {-No piracy } \\
\text {-No second- } \\
\text { hand markets } \\
\text {-Longer markets } \\
\text { for games } \\
\text {-New revenue } \\
\text { models }\end{array}$ \\
\hline $\begin{array}{l}\text { Game publishers -> } \\
\text { G-cluster }\end{array}$ & $\begin{array}{l}\text {-Content } \\
\text { (games) for the } \\
\text { platform }\end{array}$ & -References \\
\hline $\begin{array}{l}\text { G-cluster -> } \\
\text { Network operators }\end{array}$ & $\begin{array}{l}\text {-Financial value } \\
\text {-More content } \\
\text { for the services }\end{array}$ & $\begin{array}{l}\text {-Market } \\
\text { potential }\end{array}$ \\
\hline $\begin{array}{l}\text { Network operators - } \\
>\text { G-cluster }\end{array}$ & $\begin{array}{l}\text {-Delivery } \\
\text { channel } \\
\text {-IaaS services }\end{array}$ & $\begin{array}{l}\text {-Pre-existing } \\
\text { customers } \\
\text {-Marketing } \\
\text {-Brand name } \\
\text {-Networking } \\
\text { with game } \\
\text { publishers } \\
\end{array}$ \\
\hline $\begin{array}{l}\text { G-cluster -> Video- } \\
\text { on-demand service } \\
\text { providers }\end{array}$ & $\begin{array}{l}\text {-New feature for } \\
\text { the service }\end{array}$ & $\begin{array}{l}\text {-Market } \\
\text { potential }\end{array}$ \\
\hline $\begin{array}{l}\text { Video-on-demand } \\
\text { service providers -> } \\
\text { G-cluster }\end{array}$ & $\begin{array}{l}\text {-Invoicing } \\
\text { system for the } \\
\text { service }\end{array}$ & $\begin{array}{l}\text {-Networking } \\
\text { with IPTV } \\
\text { providers }\end{array}$ \\
\hline $\begin{array}{l}\text { G-cluster -> } \\
\text { Set-top box } \\
\text { manufacturers }\end{array}$ & $\begin{array}{l}\text {-New feature for } \\
\text { the service }\end{array}$ & $\begin{array}{l}\text {-Market } \\
\text { potential }\end{array}$ \\
\hline $\begin{array}{l}\text { Set-top box } \\
\text { manufacturers -> } \\
\text { G-cluster }\end{array}$ & & $\begin{array}{l}\text {-Networking } \\
\text { with IPTV } \\
\text { providers }\end{array}$ \\
\hline $\begin{array}{l}\text { G-cluster -> } \\
\text { Middleware } \\
\text { software providers }\end{array}$ & $\begin{array}{l}\text {-New feature for } \\
\text { the service }\end{array}$ & $\begin{array}{l}\text {-Market } \\
\text { potential }\end{array}$ \\
\hline $\begin{array}{l}\text { Middleware } \\
\text { software providers - } \\
>\text { G-cluster }\end{array}$ & & $\begin{array}{l}\text {-Networking } \\
\text { with IPTV } \\
\text { providers } \\
\end{array}$ \\
\hline G-cluster -> Portals & $\begin{array}{l}\text {-Financial value } \\
\text {-More content } \\
\text { for the services }\end{array}$ & $\begin{array}{l}\text {-Market } \\
\text { potential }\end{array}$ \\
\hline $\begin{array}{l}\text { Portals -> } \\
\text { G-cluster }\end{array}$ & $\begin{array}{l}\text {-Delivery } \\
\text { channel } \\
\text {-Menu for the }\end{array}$ & $\begin{array}{l}\text {-Pre-existing } \\
\text { customers } \\
\text {-Marketing } \\
\end{array}$ \\
\hline
\end{tabular}




\begin{tabular}{|l|l|l|}
\hline & games & -Brand name \\
\hline G-cluster -> Server & -New feature for & -Market \\
manufacturer & the services & potential \\
\hline Server & & -Networking \\
manufacturer -> & & with network \\
G-cluster & & operators \\
\hline
\end{tabular}

G-cluster was able to develop its market position by (i) cooperating with several partners, who benefited from the G-cluster service and marketed it forward to network operators (IaaS providers), (ii) offering unique indirect value to game publishers (content providers) in addition to direct, financial value, (iii) developing its platform further to become less dependent on third parties, and (iv) removing some partners from the value network when these became unnecessary. By cooperating with several kinds of partners, G-cluster developed its reputation and became well known among IaaS providers. Gcluster also developed its product further by including functions that were previously provided by portals or video-on-demand service providers. These actions improved the firm's network position by decreasing the importance of firms that provided mainly indirect value (set-top box manufacturers, middleware software providers, server providers), and/or by integrating within its own product functionalities that had previously been provided by portals and video-on-demand service providers. In addition, by using well known game publishers and network operators as their reference customers they were able present themselves as trustworthy PaaS provider in the cloud gaming market.

As can be observed from Figures 2-4, the value network evolved from a complex structure involving several actors (in 2005), towards a simple network structure that included only the most critical partners, the SaaS and IaaS providers (in 2013). The findings here indicate that although the number of partners in the network decreased over time, the number of content and IaaS providers increased. This is in line with the notion by Easton [18] that the more the independence of a firm increases, the less fragmented its network becomes, with improvements also in the position of the firm in the network. From the findings it appears that the PaaS provider's network evolved through the following steps: First of all, it networked with all possible actors who could benefit from the platform (SaaS providers, IaaS providers, and third parties) to achieve market visibility. Secondly, when it got more visibility in the market, it started to focus only on the key actors in the network, that is the content and IaaS providers, and expand its network with them. Thirdly, in a parallel development, it developed the platform and provided the SDK for the game publishers, and the cloud gaming console for the network providers. All these actions increased the PaaS provider's position in the value network and made it more concentrated.

\section{Conclusions}

This study contributes to IS research in several ways. First of all, although existing IS literature has examined various actors in cloud computing, the focus has been mainly on SaaS providers [4]. This study focused on a PaaS provider's value creation, and it contributes to an understanding of a PaaS provider's activities in the value network. Secondly, this study provides detailed knowledge on how a PaaS provider can cooperate with other firms and form a value network that provides complementary services for its platform. Although both value networks [1, 11, 12, 25] and platforms [2, 3] have been extensively studied in the existing literature, the value networks of PaaS providers have been underrepresented in the IS literature. Thirdly, this study incorporates network theory and literature on value creation, and extends IS research by conceptualizing the value creation and evolution of the value network in the context of cloud gaming. Specifically, the study provides an in-depth view of how a PaaS provider can create value with other actors in the network, and how the value can be used to form a good network position in the market. In addition, the study provides detailed insights on how and why the network changes over time. This is important in developing a realistic view of value creation [12] and network development [19, 20]. As Halinen and Törnroos [22] have noted, over time networks change in relation to the problems that they aim to solve and in this way, to the value they aim to create. When situations change, new kinds of actors may be needed in network cooperation, and this will lead to a change in the network structure.

From the practical point of view, this study has implications for firms that are developing PaaS offerings. The study shows that a PaaS provider's service should present a valuable and a low-risk means of expanding SaaS and IaaS providers' own service offering. In that way, a PaaS provider can gain content for the platform. This will increase the attractiveness of the platform for end-users and make possible a network externality effect. In addition, revenue sharing between the key actors (i.e. the SaaS, PaaS, and IaaS providers) can work well. In this case study, it motivated all the partners in the network to provide good services to the end-users who paid for the service. This has the potential to work better than a model in which each service provider has a customer-provider relationship with a different provider. Such a model can motivate service providers to drive forward only their own advantages, rather than the advantages that can accrue to the entire service delivered to the end-user.

The research method used here enabled an indepth and longitudinal view of the phenomenon. However, by its nature, the single-case study method requires caution as to generalization, bearing in mind the possibly context-specific nature of the findings. 
Further studies including more cases will be needed to validate the findings here. Furthermore, since the study focused solely on a game platform provider, the findings may not be fully generalizable to other types of PaaS provider. Thus, comparative studies involving different types of PaaS provider will be required in the future.

\section{Acknowledgements}

The authors would like to thank Pasi Tyrväinen for his valuable comments and suggestions. The research reported here was carried out within the framework of the Cloud Software Program, which was governed by TIVIT Oy. In addition, the Emil Aaltonen Foundation provided financial support for this study.

\section{References}

[1] Allee, V. 2008. Value network analysis and value conversion of tangible and intangible assets. Journal of Intellectual Capital 9(1), 5-24.

[2] Cusumano, M., Gawer, A. 2002. The Elements of Platform Leadership. MIT Sloan Management Review 43(3), 51-58.

[3] Gawer, A., Cusumano, M. 2008. How Companies Become Platform Leaders. MIT Sloan Management Review 49(2), 28-35.

[4] Armbrust et al. 2010. A view of cloud computing. Communication of the ACM 53(4), 50-58.

[5] Cusumano, M. 2010. Cloud computing and SaaS as new computing platforms. Communication of the ACM 53(4), 27-29.

[6] Lawton, G. 2008. Developing Software Online With Platform-as-a-Service Technology. Computer 41(6), 13-15.

[7] Beimborn, D., Miletzki, T., Wenzel, S. 2011. Platform as a Service (PaaS). Business \& Information Systems Engineering 3(6), 381-384.

[8] Boniface et al. 2010. Platform-as-a-Service Architecture for Real-Time Quality of Service Management in Clouds. 2010 Fifth International Conference on Internet and Web Applications and Services (ICIW), 155-160.

[9] Håkansson, H., Johanson, J. 1992. A Model of Industrial Networks, In: Axelsson, B. and Easton, G. (eds.), Industrial Networks. A New View of Reality, London: Routledge, pp. 28-36.

[10] Johanson, J., Mattsson, L-G. 1988. Internationalisation in Industrial Systems - A Network Approach. In Hood, N. and Vahlne, J-E. (eds.), Strategies in Global Competition, Croom Helm, London, pp. 287314.

[11] Allee, V. 2000. Reconfiguring the value network. Journal of Business Strategy 21(4), 36-39.

[12] Walter, A., Ritter, T., Gemünden, H.G. 2001. Value creation in buyer-seller relationships. Industrial Marketing Management 30(4), 365-377.

[13] Hugos, M.H., Hulitzky, D. 2011. Business in the Cloud: What Every Business Needs to Know About Cloud Computing. John Wiley \& Sons, Inc.

[14] Gens, F. 2009. Defining "Cloud Services" -an IDC update. IDC exhanges. blogs.idc.com/ie/?p=422.

[15] Johanson, J., Vahlne, J-E. 2003. Business Relationship Learning and Commitment in the Internationalization process. Journal of International Entrepreneurship 1(1), 83-101.

[16] Zhang, Q., Cheng, L., Boutaba, R. 2010. Cloud computing: state-of-the-art and research challenges. Journal of Internet Services and Applications 1(1), 718.

[17] Gulati, R. 1999. Network location and learning: the influence of network resources and firm capabilities on alliance formation. Strategic Management Journal 20, 397-420.

[18] Easton, G. 1992. Industrial Networks: A Reviw, In: Axelsson, B. and Easton, G. (eds.), Industrial Networks. A New View of Reality, London: Routledge, pp. 3-27.

[19] Larson, A., Starr, J.A. 1993. A Network Model of Organization Formation. Entrepreneurship Theory and Practice 17(2), 5-15.

[20] Prashantham, S., Dhanaraj, C. 2010. The Dynamic Influence of Social Capital on the International Growth of New Ventures. Journal of Management Studies 47(6), 967-994.

[21] Kothandaraman, P., Wilson, D.T. 2001. The Future of Competition: Value-Creating Networks. Industrial Marketing Management 30(4), 379-389.

[22] Halinen, A., Törnroos, J.Å. 2005. Using case methods in the study of contemporary business networks. Journal of Business Research 58(9), 1285-129.

[23] Lapierre, J. 2000. Customer-perceived value in industrial contexts, Journal of Business \& Industrial Marketing 2/3,122 - 145 .

[24] Parolini, C. 1999. The Value Net. A Tool for Competitive Strategy, John Wiley \& Sons Ltd: Great Britain.

[25] Ojala, A., Tyrväinen, P. 2011. Value networks in cloud computing. Journal of Business Strategy 32(6), 40-49.

[26] Darke, P., Shanks, G., Broadbent, M. 1998. Successfully completing case study research: combining rigour, relevance and pragmatism. Information Systems Journal 8(4), 273-289.

[27] Pettigrew, A.M. 1990. Longitudinal Field Research on Change: Theory and Practice. Organization Science 1(3), 267-292.

[28] Yin, R.K. 2009. Case study research: Design and methods. CA: SAGE Publications.

[29] Edmondson, A.C., McManus, S.E. 2007. Methodological fit in management field research. Academy of Management Review 32(4), 1155-1179.

[30] Eisenhardt, K.M., Graebner, M.E. 2007. Theory building from cases: Opportunities and challenges. Academy of Management Journal 50(1), 25-32.

[31] Eisenhardt, K.M. 1989. Building Theories from Case Study Research. Academy of Management Review 14(4), 532-550.

[32] Ford, D., Redwook, M. 2005. Making sense of network dynamics through network pictures: A longitudinal case study. Industrial Marketing Management 34(7), 648-657.

[33] Huber, G.P., Power, D.J. 1985. Retrospective Reports of Strategic-level Managers: Guidelines for Increasing their Accuracy. Strategic Management Journal 6, 171180.

[34] Miles, M.B., Huberman, A.M. 1994. Qualitative Data Analysis: An Expanded Sourcebook. California: Sage Publications. 